\title{
TECHNOLOGIES FOR RAPID PROTOTYPING (RP) - BASIC CONCEPTS, QUALITY ISSUES AND MODERN TRENDS
}

\author{
Roussi Minev ${ }^{1}$, Ekaterin Minev ${ }^{2}$ \\ ${ }^{1}$ Department of Material Science and Technology, Ruse University "A. Kanchev" \\ ${ }^{2}$ Department of Computer Science, Ruse University "A. Kanchev"
}

\begin{abstract}
The paper describes the basics of the 3D printing technologies for rapid prototyping (RP). It shows the benefits of their utilization in product design and manufacturing of conventional parts and items with medical and other application. The most mature RP principles are presented and compared.
\end{abstract}

Some trends in developing new 3D printers and corresponding materials for micro/nano and biological applications are described. Some modern budget platforms are suggested for technology users.

The paper also provides a summary of the main quality issues in the layering technologies as well as methodologies for studying the process capabilities, accuracy and maturity.

Keywords: Rapid Prototyping, 3D printers, Medical devices, Prosthetics

\section{INTRODUCTION}

The broader concept of "prototyping" represents an approximation of a product or a system and its components in some form for a definite purpose such as its study or experimental implementation. Mathematical or computer models and graphic sketches are a typical example of object approximations and could be described as virtual prototypes (1). Foam models, functional physical approximations and precise plastic or metal replica of some objects are physical prototypes.

In so-called "agile manufacturing" (a term applied to the processes that enable quick respond to customer needs and market changes as well as product customization (2)) a crucial factor becomes the

Address for correspondence:

Roussi Minev

Department of Material Science and Technology

Ruse University

8 Studentska Str,

7017 Ruse

e-mail:rus@uni-ruse.bg

Received: April 25, 2015

Accepted: May 11, 2016 development of supporting manufacturing technology that allows the designers and makers to share a common information database of parts, products, tools and production capacities. This is particularly important in the production of medical items, prosthetic devices and dental implants where small initial problems may have larger downstream effects. For these technologies and services the lead time to a product is of paramount importance and the fast preparation of prototypes by $3 \mathrm{D}$ printing can shorten the time to customer and significantly reduce the price and number of nonconformity items. As seen on Fig. 1 the typical cycle of product development follows several stages - from product design to functional testing. The effect of $3 \mathrm{D}$ printing or the so-called Rapid Prototyping (RP) technologies is to shorten the development cycle of new manufacturing or medical products down to $50 \%$ of the initial one (3). With the help of RP 3D printing technologies, agile manufacturing is becoming the next step in the evolution of production methodology after the lean manufacturing approach that leads to the elimination of waste, e.g. spare parts, models and standardized sizes of products. Since the cost of correcting quality issues increases as the problem moves downstream it is cheaper to correct problems with the help 
of RP models and RP tools at the earliest possible point immediately after the first stage of the conceptual product design as shown on Fig. 1.
The first stage includes the creation of a $3 \mathrm{D}$ model using a typical CAD software and followed by a process of conversion of the file in a specific STL

\begin{tabular}{|c|c|c|c|c|c|c|c|c|}
\hline \multicolumn{2}{|c|}{ product design } & \multicolumn{2}{|c|}{ part drawing } & \multicolumn{2}{|c|}{ tool design } & tool manufacturing & assembly and test & function testing \\
\hline \multirow[t]{2}{*}{\begin{tabular}{|l} 
product \\
design
\end{tabular}} & \multirow[t]{2}{*}{\begin{tabular}{|c|}
$\mathrm{RP}$ \\
model
\end{tabular}} & deol & \multicolumn{3}{|c|}{$\begin{array}{c}\text { tool } \\
\text { manufacturing }\end{array}$} & \multicolumn{3}{|c|}{ 3D Printers - Rapid Prototyping and Tooling } \\
\hline & & $\begin{array}{c}\mathrm{RP} \\
\text { tool }\end{array}$ & \multicolumn{2}{|c|}{ assembly } & $\begin{array}{l}\text { function } \\
\text { testing }\end{array}$ & $\begin{array}{l}\text { tion } \\
\text { ting } \\
\end{array}$ & & tim \\
\hline & & $25 \%$ & & & & $50 \%$ & $75 \%$ & $100 \%$ \\
\hline
\end{tabular}

Fig. 1. Time and cost compression effect of $3 D$ printing implementation on product design and development. RP models and tools could shorten the lead time down to 50\% of the initial one

\section{The Rapid Prototyping Concepts}

Rapid Prototyping (RP) can be defined as a group of techniques used to quickly fabricate a scale model of a part or assembly using three-dimensional computer aided design (CAD) data. RP has also been referred to as: solid free-form manufacturing, computer automated manufacturing, layered manufacturing. The typical process chain of RP with the use of various $3 \mathrm{D}$ printers (3) includes several stages as presented on Fig. 2. format. The STL (STereoLithography or Standard Tessellation Language) file is the most common file format to convey $3 \mathrm{D}$ data to the RP system. The file consists of unordered list of triangular facets representing the outer layer of an object. In ASCII format the files consist of coordinates of the triangle's vertexes and description of the facets normals (cosines of the angle between the facets normal and the coordinate axes).

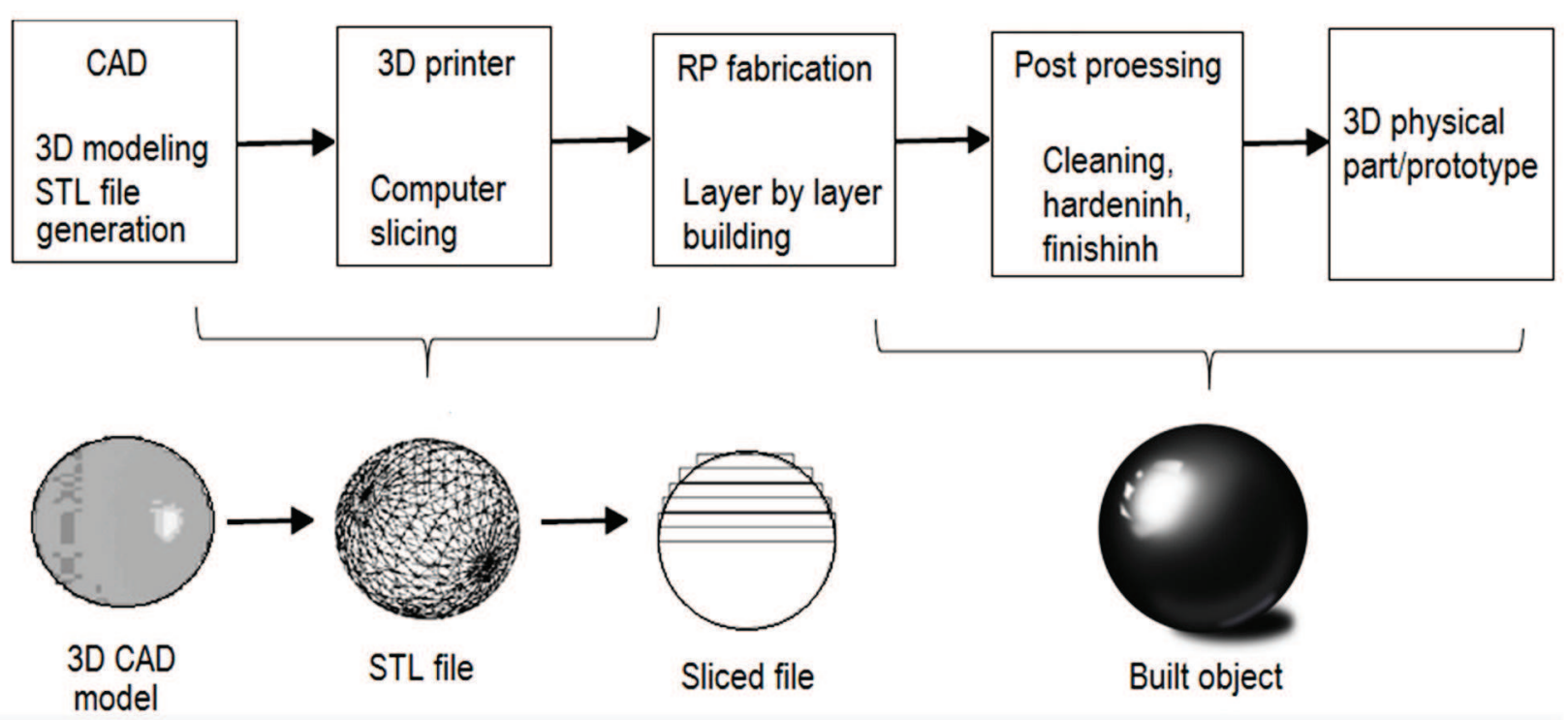

Fig. 2. The typical RP process chain 
Technologies for Rapid Prototyping (RP) - Basic Concepts, Quality Issues and Modern Trends

The second stage includes digital slicing of the STL file using a specific algorithms. The digital slicing process usually occurs on the computer platform of the 3D printer itself. As a result of the slicing we have a series of $2 \mathrm{D}$ geometries which are used for the generation of a code which at the third stage is transferred to the 3D printer control board and executed as a X-Y movement of the laser beam or the print head or the extrusion nozzle (depending on the type of technology in place). The deposition, sintering, curing or cutting of the material in an X-Y plain is followed by a movement in $\mathrm{Z}$ direction of the platform down (or print-head - up) and then the X-Y movement is repeated. Thus, the object is built layer by layer.

Most of the RP 3D printing processes will require a fourth stage - post-processing operations such as (i) cleaning or washing of the excess of powder or liquid material; (ii) cleaning or dissolving of the support material (used to prevent leaking or falling of the low viscosity raw material when lower or downcast surfaces of the object are produced); (iii) post-curing of photopolymers to achieve full solidification; (iv) infiltration of the material with additional substances for improving their mechanical properties (e.g. wax infiltration of the polystyrene investment-casting patterns); (v) painting, polishing and other surface treatment.

The most popular classification of the RP processes (Table 1) is based on the physical state of the pattern raw material which could be: liquid, powder, sheet, gas $(3,4)$. About forty technological approaches to RP have been identified (5). The description given in Table 2 below does not cover all of the existing processes but represents the most common commercial platforms which have reached maturity today.

The physics and basic mechanics of the processes are described below and depicted on Fig. 2.

$\begin{aligned} & \text { Table 1. Classification of the RP processes according to the } \\
& \text { physical state of the pattern raw material }\end{aligned}$
\begin{tabular}{l|c|cc}
\hline $\begin{array}{l}\text { Liquid } \\
\text { phase }\end{array}$ & $\begin{array}{c}\text { Powder } \\
\text { form }\end{array}$ & Sheet form & Gas phase \\
SLA & SLS & LOM & SALD \\
FDM & 3D-P & & \\
MJM & LENS & & \\
SDM & & & \\
\hline
\end{tabular}

\section{SLA - Stereolithography}

It is using photopolymerization, a process by which light causes chains of molecules to link together, forming polymers. The light used for the polymerization is either laser beam controlled by a scanning system or DLP (digital light projection) image.

\section{FDM - Fused Deposition Modeling}

Plastic filament is led to an extruder head where it is molten and forced out through small diameter jet onto the part surface where it solidifies.

\section{MJM - Multi Jet Modeling}

The process uses piezo print head technology to deposit either photocurable plastic resin or casting wax materials layer by layer using multiple nano size jets. Support structures will be generated automatically and removed by solving or melting.

\section{SDM - Shape Deposition Manufacturing}

Alternate deposition and shaping (machining) of layers of part material and sacrificial support material.

\section{SLS - Selective Laser Sintering}

Uses a laser to sinter powdered material (polymer, metal, ceramic). The laser automatically scans the space defined by the 2D slice of a 3D model, binding the material particles together to create a solid structure.

\section{D-P 3D Printing}

It uses standard inkjet printing technology to create parts layer-by-layer by depositing a liquid binder onto thin layers of powder.

\section{LENS - Laser Engineered Net Shaping}

A metal powder is injected into a molten pool created by a focused, high-powered laser beam

\section{Laminated Object Modeling}

Layers of adhesive-coated paper, plastic, or metal laminates are successively glued together and cut to shape with a knife or a laser cutter.

\section{SALD - Selective Area Laser Deposition}

The process that uses a volatile liquid or gaseous chemical precursor that diffuses to the substrate surface. Scanning with a laser (or an ion beam) across the substrate, selectively heats it, forming deposits of ceramic or metal material (6).

The existence of a great variety of RP 3D printing technologies is because each of them have different advantages and drawbacks in terms of reliabili- 


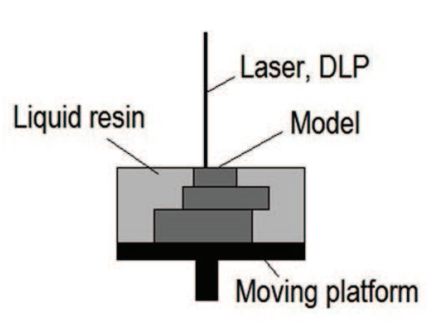

SLA

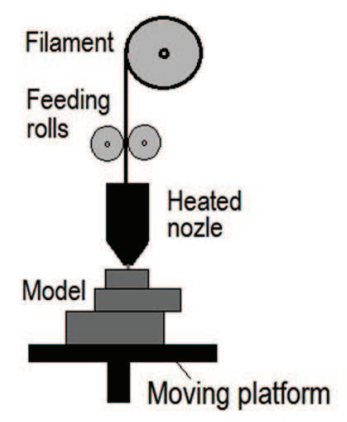

FDM

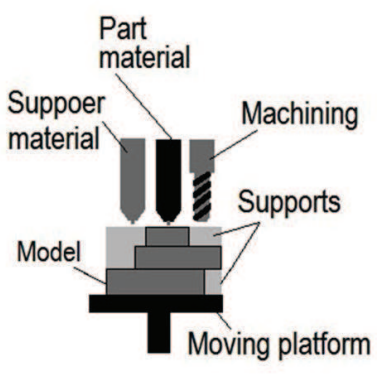

SDM

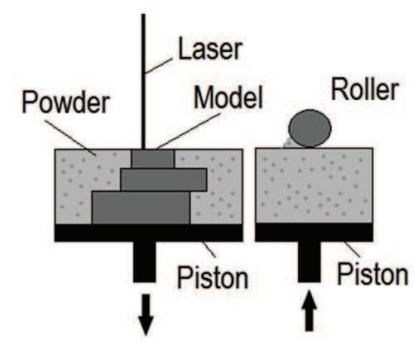

SLS

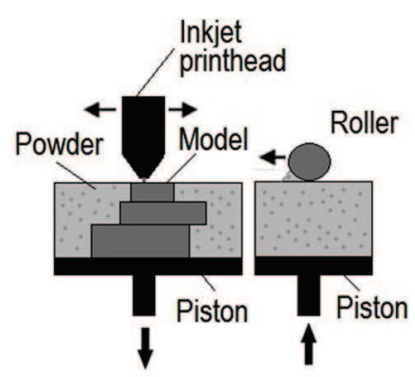

3D-P

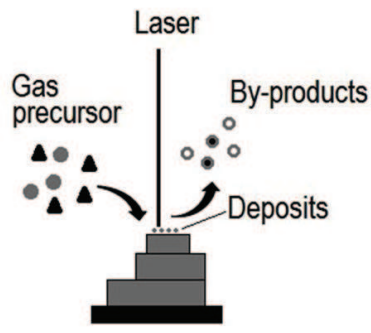

SALD

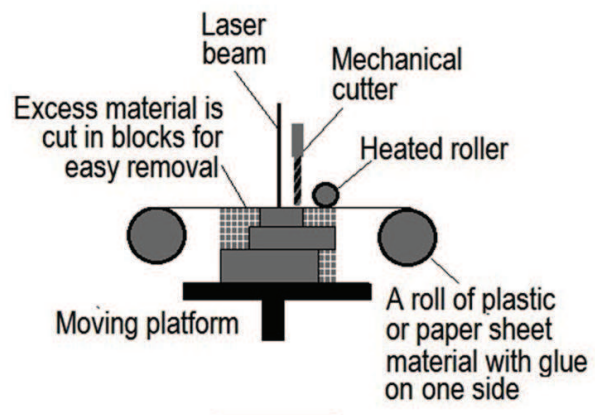

LOM

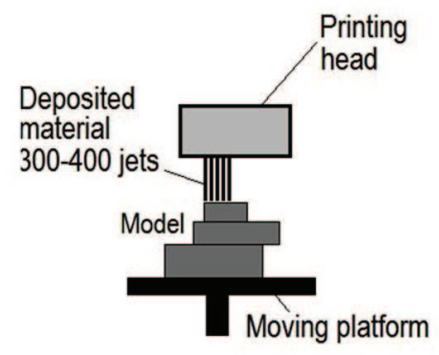

MJM

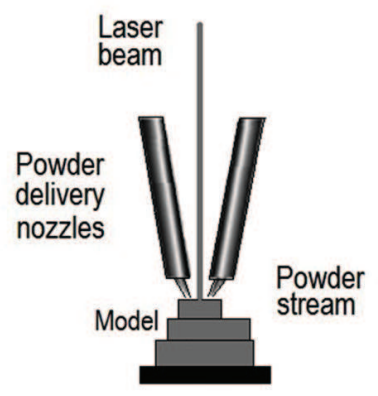

LENS

Fig. 3. Pictograms of the RP 3D printing processes described in Table 1

ty and repeatability of the process, parts quality, accuracy, dimensional stability, availability and cost effectiveness. Table 2 represents comparative study of some processes and summarizes the authors experience in the use of the 3D printing technologies.
Quality Issues of the 3D Printing RP

Technologies $(3,4,7,8)$

Problems with the Digital Model

Geometry flaws may occur in the STL files because of the imperfections in the algorithms that convert the 3D specific file in a tessellation file. The types of errors in STL files are: missing facets, degenerate facets with collinear edges and no valid sur- 
Technologies for Rapid Prototyping (RP) - Basic Concepts, Quality Issues and Modern Trends

Table 2. Comparison of the basic RP systems

\begin{tabular}{|c|c|c|}
\hline Technology & Advantages & Disadvantages \\
\hline SLA & $\begin{array}{l}\text { Excellent quality surface } \\
\text { Complex geometry } \\
\text { Good accuracy }\end{array}$ & $\begin{array}{l}\text { Support structures } \\
\text { Parts deform easily } \\
\text { The vapours are harmful }\end{array}$ \\
\hline SLS & $\begin{array}{l}\text { No need for further sintering } \\
\text { No need of supports } \\
\text { High range of materials }\end{array}$ & $\begin{array}{l}\text { The surfaces are rough and porous } \\
\text { Long time and considerable energy } \\
\text { Patterns for precision castings requires } \\
\text { additional processing (infiltration) } \\
\text { Significant distortions }\end{array}$ \\
\hline LOM & $\begin{array}{c}\text { Details can be further processed (polished, } \\
\text { drilled) } \\
\text { Ability to manufacture large parts quickly and } \\
\text { cheaply }\end{array}$ & $\begin{array}{l}\text { Thin walls have low strength } \\
\text { Readily absorb moisture } \\
\text { The separation of the parts is difficult. }\end{array}$ \\
\hline FDM & $\begin{array}{c}\text { A wide range of polymeric materials available } \\
\text { The machines are easily adjusted and used in } \\
\text { an office environment }\end{array}$ & $\begin{array}{c}\text { Support structures } \\
\text { Low strength in the vertical direction } \\
\text { The process is slow } \\
\text { Rough 'textured' outer surface } \\
\text { Problematic for tool manufacture }\end{array}$ \\
\hline MJM & $\begin{array}{l}\text { Suitable for an office environment } \\
\text { The build time is short. }\end{array}$ & $\begin{array}{c}\text { The supports are removed and leave traces, } \\
\text { which limits their use for casting models. } \\
\text { Strength is low. }\end{array}$ \\
\hline $3 \mathrm{D}-\mathrm{P}$ & $\begin{array}{c}\text { Short deadlines and cheap raw materials } \\
\text { No supporting structures } \\
\text { Complex geometry }\end{array}$ & $\begin{array}{c}\text { Delicate details not possible to produce } \\
\text { Infiltration is necessary } \\
\text { Rough surface. }\end{array}$ \\
\hline
\end{tabular}

face normal, overlapping facets (numerical roundoff can cause the facets to overlap if tolerances are set high), non-manifold topology conditions (e.g. if one edge shares more than two facets). Only a valid $3 \mathrm{D}$ model could be sliced in 2D layers and converted into scan lines of the laser beam or deposition nozzle by the controller. As an example, a missing facet in the model would cause the system to have no pre-defined stopping points and the building process would continue to the geometrical limits of the RP machine (Fig. 4).

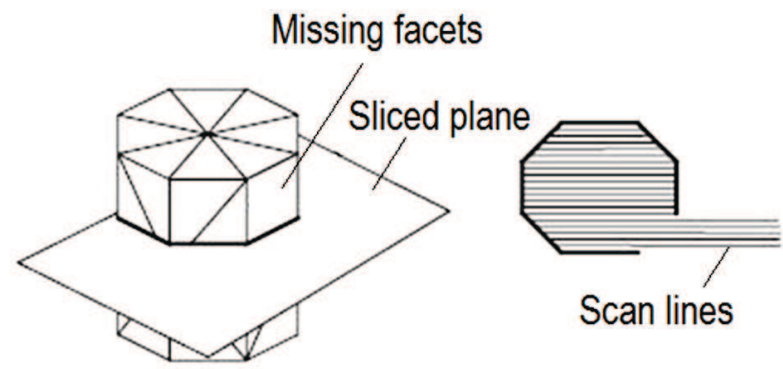

Fig. 4. Non-valid digital models may cause unconformities of the built parts
The manual shell repair is time-consuming and tedious. Some types of software may repair the nonvalid digital models automatically. They will first detect the boundaries of the gaps and then generate suitable facets to patch them up.

\section{Geometrical Problems}

Curling

Curling is a phenomenon identified when the edges or the corners of the part rise above the partbed surface. The corners of the parts may get thinner in the $\mathrm{Z}$ axis (Fig. 5a). This phenomenon occurs due to a temperature difference between the ready (sintered, cured, extruded) part and the newly added material. Curl can also occur if the part-bed temperature is too low. As a result, there are parts that are not flat, especially where large surface-area crosssections are concerned and the part may move in the part-bed when the building process is continuing. As a corrective measure, increase the set point values for the process heaters or the power of the laser. 


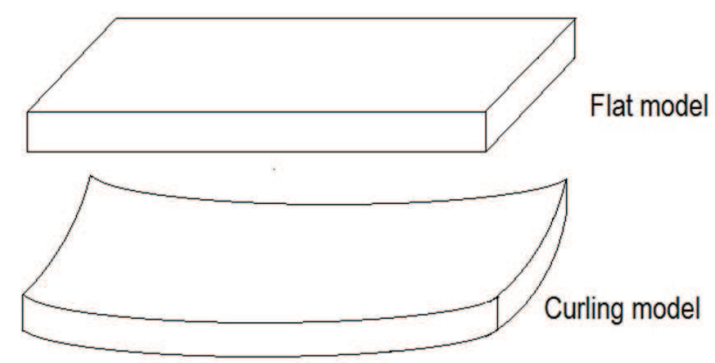

(a)
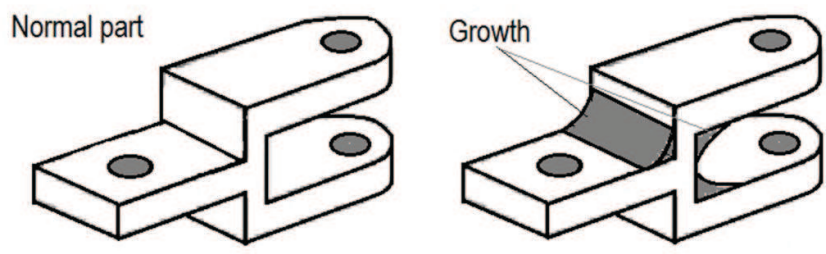

(b)

Fig. 5. Curling (a) and growth (b) problems in RP

\section{Growth}

Growth is a phenomenon identified when extra material is sintered or cured on the part, changing its dimensions (Fig. 5b). In powder sintering processes the growth occurs due to excessive laser power and part-bed temperatures, thus leading to heat diffusion beyond the part boundaries resulting in oversized parts and parts which may be difficult to break out. In photo-curable technologies such as SLA the processes are similar and it is due to the penetration of light outside the geometric boundaries of the part.

To avoid this problem, reducing part-bed temperature and the laser power is recommended.

\section{Orientation Problems}

The process accuracy in the $\mathrm{X}$ and $\mathrm{Y}$ plane is usually better that in the $\mathrm{Z}$ direction. For this reason and because no curling and growth are affecting upward surfaces the best feature definition and resolution are achieved in X-Y plane. This means that the important surfaces should be oriented upwards in the building envelope.

\section{Optical Problems}

Some optical problems (monochromatic aberration and astigmatism) may occur when a laser or a UV beam is used for curing or sintering the parts. Monochromatic aberration (Fig. 6a) occurs for some areas of the built model which lie away from the optical axis. To solve the problem different laser spot size compensations in $\mathrm{X}$ and $\mathrm{Y}$ directions are required. Astigmatism (Fig. 6b) occurs when the optical system is not symmetric about the optical axis because of a manufacturing error in the surfaces of the components or because of a misalignment of the components. The astigmatism is observed even for rays from on-axis object points.
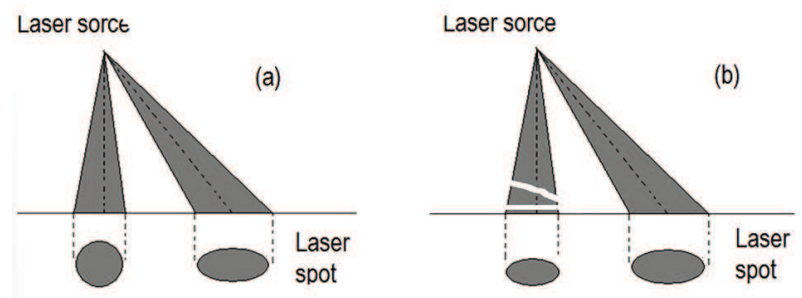

Fig. 6. Monochromatic aberration (a) and astigmatism (b) in the laser systems

\section{Thermal Contraction Problems}

This phenomenon accompanies most of the 3D printing (sintering, photo-curing, extruding) technologies and is one of the most important. It is a natural process of shrinkage due to the thermal contraction and phase transition. The process must be regularly studied and assessed together with the influence of the size of the beam (beam offset) or the size of the extruded steam. A specific 'pyramid' test piece is usually built out (Fig. 7, a) to study these factors as well as to calibrate the process. The size of the pyramid steps is measured and compared with the nominals.

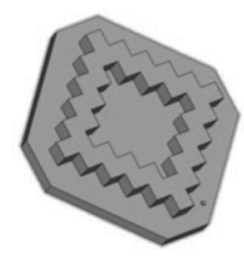

(a)

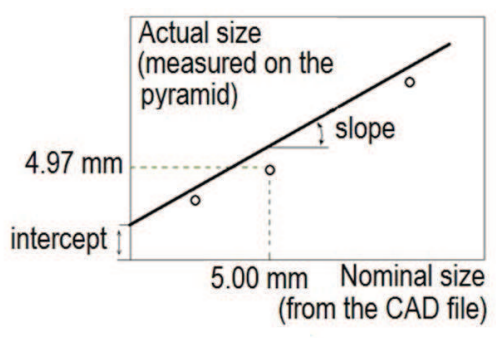

(b)
Fig. 7. The test peace (a) and a graph (b) for calibration of an RP $3 D$ printing system 
Technologies for Rapid Prototyping (RP) - Basic Concepts, Quality Issues and Modern Trends

Fig. $7 \mathrm{~b}$ shows pyramid steps size data plotted in coordinates 'nominal size - actual size'. The slope of the interpolation graph is interpreted as the 'scaling factor' (e.g. $k=0.997$ ) which has to be applied to the part dimensions (resizing the CAD model) in order to achieve closer approximation of the real part dimensions to the nominal. The intercept that the interpolation line cuts from the vertical coordinate axis of the graph gives the size of the systematic error due to the size of the laser beam (beam offset, e.g. $0.2 \mathrm{~mm}$ ) or due to the extruded plastic jet (deposited onto the sample). This beam offset also needs to be taken into consideration when resizing the CAD model.

\section{The Trend Towards Cheap Desktop 3D Printing $(9,10)$}

The liquid polymers deposition from a wire as a raw material (FDM type of technology) is the most implemented in the cheap and affordable RP machines such as RepRap (short for "replicating rapid prototype" - a self-replicating machine). It is followed by SLA (11) and LOM (12) machines that are also developed in desktop versions.

The RepRap technology was introduced in 2005 by Adrian Bowyer - professor at the Bath University, UK. The 3D printer of this class is made of plastic parts that the device should be able to produce itself. The self-replicating parts, together with the standard and widely available components such as motors, belts, electronic boards, as well as free software, enable the replication of the machine in non-industrial conditions. One of the main objectives of the RepRap project is the implementation of such 3D printers at home for various technology purposes and designs including hobby projects and art (13). The last step in the RepRap concept developed after 2013 is the creation of an affordable machine for the production of plastic filament - the raw material for building details. Thus the price of the material would drop down, creating conditions for amateur experimentation and research in the field of materials. Currently there are more than 20 manufacturers of RepRap machines and this segment is the most rapidly developing one.

\section{Rapid Prototyping of Disruptive Micro systems and Devices}

3D printing technologies for direct production of complex 3D structures have recently attracted an interest within the field of micro technology (e.g. microfluidics, lab on a chip, drug delivery systems, wearable electronics, MEMs, implants and modelling of tissues and organs). These are conventional layering technologies which are scaled down to micro level and could be described as Micro Rapid Prototyping methods $(\mu-\mathrm{RP})$.

Micro RP techniques allow for direct fabrication of 3D microstructures in one single step. In comparison, standard replication methods for fabrication of micro devices such as micro injection moulding, hot embossing, and lithography are multistep manufacturing methods which require the creation of a replication master before producing the final device (14). These replication methods, while particularly useful for industrial scale manufacture, are often expensive and time-consuming on a smaller scale owing to the need for fabrication of the replication master. Alternatively, direct micro-fabrication methods such as CNC milling and laser surface ablation allow for direct fabrication of micro structures on a variety of substrates, including glass, polymers, ceramics and metals. Micro-SLA as well as extrusion processes such as FDM can also create similar structures by additive bottom up strategy.

All these methods typically produce open channels on the surface, which in the case of microfluidics need to be sealed by an additional layer creating a channel. In this case another RP single step technology which uses direct internal 3D laser writing method comes to help. Recently, ultrafast (ultrashort pulse) lasers have also allowed the developing of new methods for production of internal microfluidic channels within the bulk of glass and polymer materials by Direct Internal 3D Laser Writing (14).

We also see lots of developments in 3D Bio Printing technologies (based on the principles of inkjet, micro extrusion and laser-assisted processes). These are implemented in the development of various biocompatible materials, cell cultivation systems and complex supporting components in the regenerative medicine (15). 
Micro RP technologies are involved in the development of numerous advanced and so-called disruptive products with functional and length scale integration (FLSI) characteristics. Such systems will include functions that require different length scale features, for instance nano electronics, various micro sensors, micro and/or nano actuators or microfluidic devices, encapsulated in a single container $(16,17,18)$. There is a trend for integrating multiple functions in as small as possible enclosures/packages. One of the cutting edge developments which require integrated design and manufacturing approach based on the RP (19) are the polymer-based lab-on-chip platforms (e.g. for protein detection in point-of-care applications). The typical lab-on-a-chip device incorporates the functionalities of a biological laboratory on a single substrate through a network of microfluidic channels, reservoirs, valves, pumps, micro-sensors and optical waveguides produced by ultrashort pulse lasers to achieve high sensitivity, analysis speed, low sample consumption, and measurement automation (19). A typical example is the impedimetric micro-biosensor array for pesticide detection (20) developed in MIT, Bucharest. The micro-biosensor array contains six biosensor chips integrated into a microfluidic system providing all fluids for biosensor activation and inhibition, electrically connected to electronic modules for signal processing and data acquisition. The overall pesticide detection platform is connected into a portable apparatus of small dimensions, low-energy consumption, easy to be manipu- lated, providing independent functioning of biosensors with data acquisition from each one.

At the same time, so-called 'killer application' for FLSI devices is still anticipated. A significant amount of work still needs to be carried out in the area of design, manufacture, and integration of these systems. E.g. microfluidic component valves, micro pumps, and separation columns need to be integrated within a single platform in different designs and combinations. Thus, recent advances in rapid prototyping (RP) techniques, such as the availability of $3 \mathrm{D}$ RP equipment with much higher resolution would be able to actuate the fabrication of complex prototype designs as well as speed up the fabrication process allowing for mass production.

\section{Process Capability Issues}

The application of the conventional and micro RP technology depends on how realistic our knowledge on the capabilities of the process or process chains is. These include the knowledge on the resolution, accuracy and process tolerances. Specific test pieces and methodologies are required for studying these issues (21). One effective approach is the implementation of the so-called Grid Method (GM). It was developed under the EUMINAFab European network (22). The method is based on a square grid generated on the CAD model of a test plate and an analysis of the grid transformation after that plate is manufactured and measured.

The Grid methodology (23) utilized in the study is based on a square grid generated on the CAD
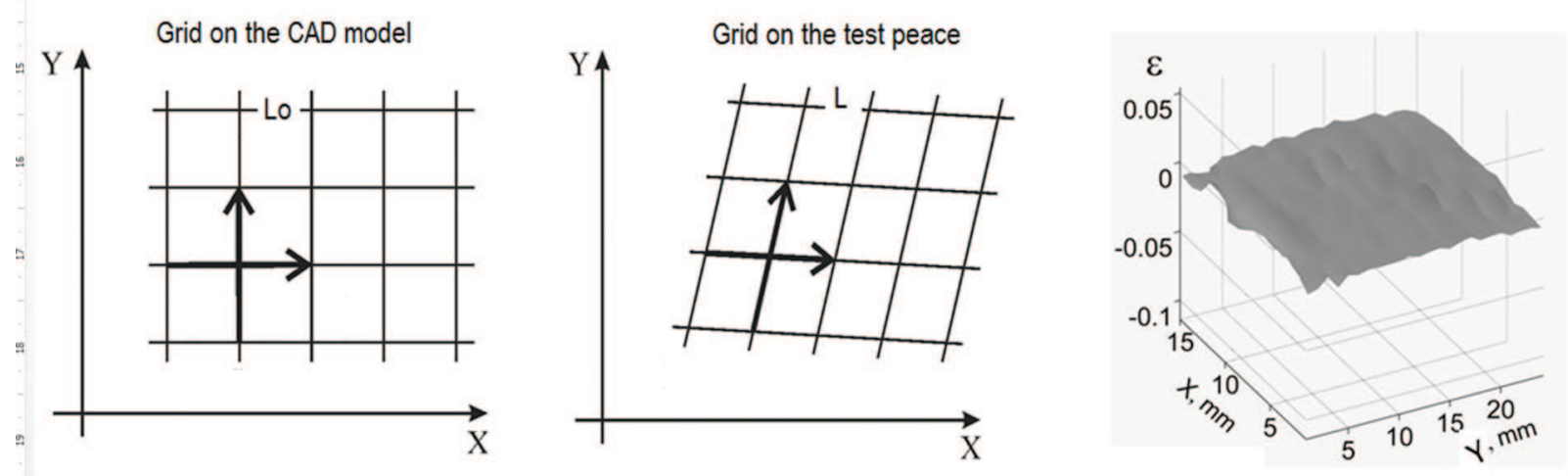

Fig. 8. The nominal grid geometry (from the CAD) - (a) and the actual grid on the test piece - (b). Distribution of the deviation (geometrical error) obtained from an SLS test piece - (c). The 3D graph shows that the deviations $(\varepsilon)$ in the X-Y plane are closely distributed around the zero. Which means that the process does not need calibration because it is accurate and the accuracy is uniform around the X-Y plane

Scripta Scientifica Medicinae Dentalis, vol. 2, No 1, 2016, pp. 12-22 
model of a test plate and a measurement and analysis of the real grid after the plate is manufactured. The estimate of the differences between the nominal (CAD) dimensions of the grid $\left(\mathrm{L}_{\mathrm{o}}\right)$ and the measured dimensions of the grid (L) on the built test piece are used to calculate the deviations $\varepsilon=\left(\mathrm{L}_{-} \mathrm{L}_{\mathrm{o}}\right) / \mathrm{L}_{\mathrm{o}}=\Delta \mathrm{L} / \mathrm{L}_{\mathrm{o}}$ for all elements of the grid.

The methodology enabled the collection of a large amount of data from a single test piece providing reliable results. The data could be represented in a $3 \mathrm{D}$ graphical view that shows how the distortions of the built RP model are distributed within the whole volume of the part (Fig 8). This gives the opportunity to correct the CAD model accordingly by a more sophisticated 3D calibration procedure. Some RP machines (e.g. SLS) have built-in software functions to provide this calibration.

This methodology has some key advantages over many other techniques for accuracy evaluation of the processes: there is no shape and size contextualization hence it can easily be applied to evaluate the uncertainties of RP models with different geometries. The results of this kind of studies could be used for benchmarking and evaluating process maturity, compatibility and complementarity, with regards to both the single process and the process chains (24).

It was shown by using the grid approach that the best suited additive layering process for micro applications is Stereolithography. But so far the studies performed show that the tolerance capabilities of the $3 \mathrm{D}$ printing $\mu$ SLA process give way to micro electro discharge machining ( $\mu \mathrm{EDM})$ and micro milling processes and need further adjustment and tuning.

\section{Materials Issues}

There are some developments in using materials compatible with the bio and environmental sector. For instance, resins with improved optical transparency and biocompatibility are introduced to the market which will support the applications of 3D printing in microfluidic platforms with optical detection.

Biostable resins based on polyester/polyether oligomers with acrylate or methacrylate functions, as well as biodegradable composites of methacrylatefunctionalized polyesters have recently been devel- oped (25). These biocompatible resins have been used in SLA equipment to produce implants meeting the Intracutaneous Test standard ISO 10993-10. Another commonly used material is the Eshell supplied by EnvisionTEC which is classified as Class II - biocompatible. Improved biocompatibility of SLA-produced components could also be achieved via surface treatments (e.g. plasma or laser irradiation) to improve wettability or surface functionalization with $-\mathrm{OH}$ or $\mathrm{NH} 2$ groups to allow biomolecule attachment.

The Asigia $\mathrm{Bio}^{\text {th }}$ range of photopolymers is safe for long-term contact with skin. They are suitable for making hearing aid shells and other prosthetics to be used in direct contact with the skin. It is suggested by the supplier that the printed resin requires the application of a lacquer in a post-processing step to make it transparent.

Other resin properties to consider when fabricating microfluidic platforms by SLA are permeability to gases, hydrophobicity, and chemical stability.

All these examples give a direction for the development and utilization of materials but although promising they are still not thoroughly exploited and further demonstration of their capabilities is necessary.

\section{CONCLUSIONS}

Several trends in the modern development of the 3D printing RP technologies could be defined:

1. Transition from PR to Rapid Manufacturing as part of the global tendency towards "agile" and "lean" manufacturing. This will require development of the mechatronic systems, materials, control systems and software some of which could be adapted from the conventional manufacturing.

2. Customization of the products produced by the various 3D printing RP technologies in terms of their use, functionality and biocompatibility, size and biometrics, particularly in medical applications and bioscience.

3. Miniaturisation of the processes and further development of micro and nano scale 3D printing RP platforms with application in biology and life science, tissue and cellular engineering, etc. 
Roussi Minev, Ekaterin Minev

4. Development of cheap and affordable desktop 3D platforms which will give way to a transition from conventional consumer market to a digital catalogue market bringing the production and assembly part of the supply chain to the consumer.

\section{ACKNOWLEDGEMENTS}

The paper was presented at workshop-demonstration " $3 D$ printing - peculiarities, application and perspectives" which was held 27-28 Nov. 2015 at Faculty of Dental Medicine, Medical University of Varna, Bulgaria. The workshop was supported by the project with contract 502/19, 12 Dec 2014, of the Fund for Scientific Investigations, Ministry of Education and Science of Bulgaria.

\section{REFERENCES}

1. Law A., Kelton W. Simulation Modelling and Analyses, McGraw-Hill, ISBN 0-07-100803-9, (1991)

2. Krajevsky L., Ritzman L., Malhotra M., Operations Management - Processes and Supply Chains, PEARSON, ISBN: 9780133872132 (2010)

3. Chia K., Leong K.F., Lim C.S. Rapid Prototyping - Principles and Applications, World Scientific, ISBN-13-978-981-277-897-0, (2010)

4. Pham D., Dimov S. Rapid Manufacturing, Springer-Verlag, London LTD, ISBN 978-1-4471-0703-3, (2001)

5. Upcraft S., Fletcher R. The Rapid Prototyping Technologies, Assembly and Automation, v.23, Issue4, DOI:10.1108/01445150310698634, pp.318-330, (2003)

6. Weiss C. Selective Area Laser Deposition for the Purpose of Ceramic Joining and Repair, doctoral dissertation, (2013), University of Connecticut Graduate School Collections, http://digitalcommons.uconn.edu/cgi/viewcontent.cgi?article= 6396\&context $=$ dissertations

7. Minev E. Grid Method Studies of the Geometrical Uncertainties in Free Form and Micro Processes, A thesis submitted to the Cardiff University for the degree of Doctor of Philosophy, http://orca.cf.ac. uk/32291/1/2012MinevEPhD.pdf, (2012)

8. Kruth J. et al. Binding mechanisms in selective laser sintering and selective laser melting, Proc. of 15th Solid Freeform Fabrication Symposium, 2004, Austin, Texas, pp.26-36.
9. Minev E., Yankov E., Minev R. The RepRap Printer for Metal Casting Patternmaking - Capabilities and Application, Труды VIII Международной нучно-практической конференции „Прогрессивные литейные технологии“, НИТУ МИСиС, 16-20.11.2015, Москва, стр. 300-303, ISBN 978-5-9903239-3-3

10. Минев Е., Янков Е., Минев Р., Изработване и изгаряне на модели за леене по стопяеми модели от PLA чрез REPRAP 3D принтер, XXII International Scientific Technical Conference FOUNDRY 2015, Pleven, (2015), брой 12, стр.33 $\div 36$, ISSN 1310-3946.

11. Минев Е., Янков Е., Минев Р. Влияние на технологичните параметри на REPRAP 3D принтер върху точността и граповостта на получаваните модели, XXII International Scientific Technical Conference FOUNDRY 2015, Pleven, (2015), брой 12 , стр. $29 \div 32$, ISSN 1310-3946.

12. http://formlabs.com/

13. http://replicatorinc.com/blog/2010/02/ solido-2950-3d-printer/

14. REPRAP MAGAZINE, issue 1, February 2013, www.reprapmagazine.com

15. O'Neill et all., Advances in three-dimensional rapid prototyping of microfluidic devices for biological applications, Bio microfluidics ISSN19321058, ISBN 19321058, (2014) v.8, issue 5, p. 052112

16. Murphy S., Atala A. 3D Bio printing of Tissues and Organs, Nature Biotechnology, v. 32 no. 8, August (2014), pp. 773-785

17. Evoy S. et al., Dielectrophoretic Assembly and Integration of Nanowire Devices with Functional CSMOS Operating Circuitry, Microelectronic Engineering, (2004), v. 75, no. 1, pp. 31-42

18. Bigot S., Dimov S., Minev R., Dobrev T. Function and Length Scale Integration in Innovative Products - Technical Solutions and New Organizational Models, International Journal of Manufacturing Technology and Management (IJMTM), ISSN: 1368-2148, (2011) Vol. 23 No.3/4, pp.157-178, DOI: 10.1504/IJMTM.2011.045514

19. Dimov S., Brousseau E., Minev R., Bigot S. Micro and Nano Manufacturing: Challenges and Opportunities, Proceedings of the Institution of Mechanical Engineers, (IMEchE) Part C, Journal of Mechanical Engineering Science (2012), ISSN 09544062, v. 226 (C1), pp. 3-15 
20. Nestler J. et al. (2009) 'Polymer Lab-on-Chip systems with integrated electrochemical pumps suitable for large scale fabrication', International Journal of Adv. Manufacturing Technologies. (2009), ISSN 0268-3768, DOI: 10.1007/s00170-009-1948-4

21. Moldovan C. et al., Biosensor Array Based Platform for Pesticide Detection, Sensor Letters (2013), 11(8), pp. 1519-1523

22. Minev E., Popov K., Minev R., Dimov S., Gagov V., Packianather M. Utilizing a grid method for accuracy study of micro SLA parts, 4M Conference, Plastipolis, Oyonnax, France, 2010, ISBN: 978-98108-6555-9, pp. 257-260

23. https://ec.europa.eu/research/infrastructures/pdf/ euminafab.pdf

24. Minev E., Popov K., Minev R., Dimov S., Gagov V. Grid Method for Accuracy Study of Micro Parts Manufacturing (2011) Micro and Nano systems (MNS), ISSN: 1876-4029, DOI:10.2174/18764029111 03030263, 3 (3), (2011), pp. 263-269

25. Vella P., Brousseau E., Minev R., Dimov S. A Methodology for Maturity Assessment of Micro and Nano Manufacturing Process Chains, Proc. ICOM (2010), Wisconsin, USA, ISBN: 978-981-08-6555-9, pp.327-334

26. http://www.dsm.com/products/somos/en_US/ home.html 